\title{
Milk Allergy: A Commonly Missed Cause of Transient Pancreatitis in Infants- A Case Report
}

\author{
Victor Ortuzar-Seminario, Frances Guerra and Antoine Jeri-Yabar* \\ School of Medicine, University of Peruvian Applied Sciences, British American Hospital, Lima, \\ Peru
}

ISSN: 2637-7632

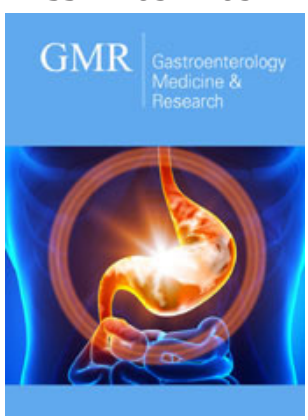

*Corresponding author: Antoine JeriYabar, School of Medicine, University of Peruvian Applied Sciences, British American Hospital, Lima, Peru

Submission:

Published: 海 June 23, 2021

Volume 6 - Issue 1

How to cite this article: Victor OrtuzarSeminario, Frances Guerra, Antoine JeriYabar. Milk Allergy: A Commonly Missed Cause of Transient Pancreatitis in InfantsA Case Report. Gastro Med Res. 6(1). GMR. 000626. 2021.

DOI: 10.31031/GMR.2021.06.000626

Copyright@ Antoine Jeri-Yabar, This article is distributed under the terms of the Creative Commons Attribution 4.0 International License, which permits unrestricted use and redistribution provided that the original author and source are credited.

\section{Introduction}

The incidence of pediatric acute pancreatitis is 3-13 cases per 100,000 persons per year [1]. There are several risk factors for infants to present acute pancreatitis including genetic associations such as SPINK1 protein, anomalies of the pancreas, gallstones, microlithiasis, medications and metabolic, hematologic and a wide variety of infections. Five to twenty percent of children with acute pancreatitis have pancreatic anomalies, making it one of the most common causes of pancreatitis in this population [1] only preceded by genetic associations. Milk allergy is the most common food allergy in young children and its prevalence is higher in infants than young children. There have been a few case reports that link milk allergy to acute transient pancreatitis most commonly in infants as well. Herein, we present a case of milk allergy induced pancreatitis in a 1-year-old patient from Lima-Peru.

\section{Case Presentation}

A previously healthy 1-year-old male with a history of milk protein allergy and a mild respiratory tract infection 1 week before with no major treatment began presenting 18 hours before admission irritability and abdominal distension. 16 hours before admission the patient presents 2 vomits with alimentary content associated with abdominal pain. A home doctor is called and prescribes rehydration formula, but the infant presents oral intolerance and continues to vomit. Somnolence and dehydration are added 10 hours before admission, and the parents decide to take him to the emergency department where he is admitted to the pediatric ICU and rehydrated intravenously. According to his past medical history, the infant was born by a C-section with a birth weight of $3,400 \mathrm{~kg}$, and had physiologic anemia at 8 months, which reverted with iron treatment. Family history was positive for asthma, diabetes mellitus 2 and pancreatitis.

Upon examination, the infant was irritable, seemed dehydrated and in a poor general state. His vital signs were blood pressure of $105 / 58$, a temperature of $36.9^{\circ} \mathrm{C}$, respiratory rate of 34 breathes per minute. Lungs were clear to auscultation bilaterally, with no aggregated sounds. No heart murmurs were present during auscultation of the heart; the S1 and S2 sounds were normal and rhythmic. The abdomen was visually distended, tender to deep palpation, active bowel sounds were present on auscultation on the four quadrants of the abdomen. A complete blood count, hepatic laboratory tests, amylase, lipase and CT scan of the abdomen were ordered. Results are shown on Table $1 \& 2$. The CBC showed eosinophilia (1309), the rest was normal.

Table 1: Laboratory values.

\begin{tabular}{|c|c|c|c|}
\hline & $\mathbf{1 1 / 1 2 / 2 0}$ & $\mathbf{1 1 / 1 4 / 2 0 2 0}$ & $\mathbf{1 1 / 1 5 / 2 0 2 0}$ \\
\hline Lipase & $1632 \mathrm{U} / \mathrm{L}$ & $28 \mathrm{U} / \mathrm{L}$ & $14 \mathrm{U} / \mathrm{L}$ \\
\hline Amylase & $662 \mathrm{U} / \mathrm{L}$ & $69 \mathrm{U} / \mathrm{L}$ & $60 \mathrm{U} / \mathrm{L}$ \\
\hline
\end{tabular}


Table 2: Laboratory values.

\begin{tabular}{|c|c|c|}
\hline Complete Blood Count & \multicolumn{2}{|c|}{$\mathbf{1 1 / 1 4 / 2 0}$} \\
\hline Hemoglobin & 11.00 & $\mathrm{~g} / \mathrm{dl}$ \\
\hline Hematocrit & 32.9 & $\%$ \\
\hline WBC & 10.90 & $\times 10^{\wedge} 6 / \mathrm{ul}$ \\
\hline Eosinophil \% & 12.0 & $\%$ \\
\hline Eosinophil & 1309.00 & $\times 10^{\wedge} 3 / \mathrm{ul}$ \\
\hline Platelets & 409 & $\times 10^{\wedge} 3 / \mathrm{ul}$ \\
\hline
\end{tabular}

The CT scan suggested the presence of peripancreatic edema and dilation of the biliopancreatic ducts (Balthazar A), and also a papilobiliopancreatic protrusion towards the lumen of the second portion of the duodenum was informed. Due to the assumption of pancreatitis due to a congenital anomaly, an abdominal MRI and a Colangio-MRI was performed three days later, which showed normal anatomy and no other anomalies as seen on Figure 1. A pediatric gastroenterologist was called to the case and ordered several exams to rule out all other possible causes of pancreatitis. Antibodies for Epstein Barr, Herpes, Toxoplasma, Citomegalovirus, Rubeola were ordered and came back negative. A complete parasitologic exam was also negative. During the hospital stay the patient was hydrated and was given omeprazole, ondansetron, acetaminophen. Due to the patient's favorable evolution and normalization of lipase and amylase levels, he was translated to the Pediatric Floor where he stayed for 3 days with no abdominal pain or vomits and was then discharged with no further complications.
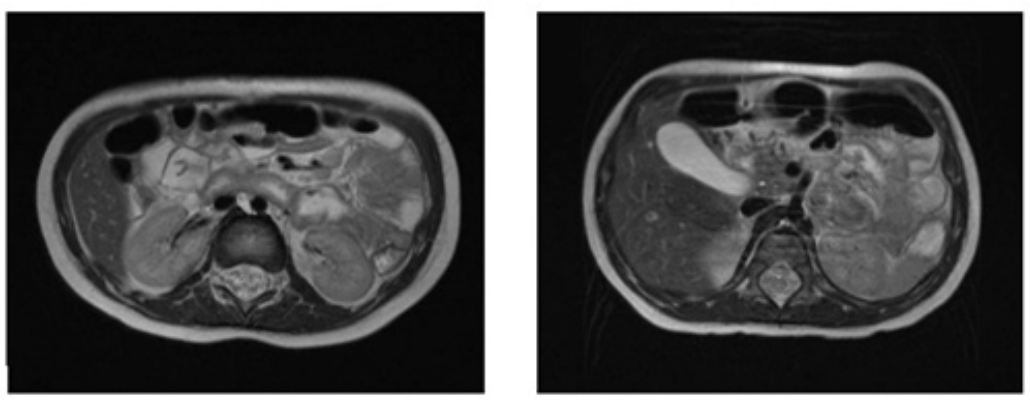

Figure 1: MRI of the abdominal cavity shows no inflammatory changes or lesions.

\section{Discussion}

The clinical manifestations of acute pancreatitis in infants are irritability, sudden onset abdominal pain with elevation of pancreatic enzymes in the serum; also associated with nausea and or vomiting [2]. There are 3 major imaging methods that can be used in the infant population when suspecting acute pancreatitis. A trans abdominal ultrasound is the best initial imaging study of choice to screen for this disease but it can be very difficult to perform depending on the age of the patient [3] and also pancreatic enlargement has been reported to be absent in $50 \%$ of patients ultrasounds [4]. An abdominal CT scan helps determine with more clarity the peripancreatic edema and/or collections and also can give a clearer image of the biliary tract, but pancreatic or biliary tract malformations are best seen with an MRI [3]. In this particular case, anatomic malformations and infectious causes were ruled out, leaving us with the diagnosis of probable pancreatitis due to milk allergy, which has been reported, in few prior case reports. The cause of pancreatitis is assumed to be pancreatic eosinophilic inflammation and local duodenal inflammation [5]. It is also worth to notice that pancreatitis due to milk allergy is transient with rapid improvement, which could be seen in our patient through imaging since control MRI showed no signs of pancreatitis 3 days after a pathologic CT scan as well as laboratory improvement. It is important to take into account this cause of pancreatitis in infants due to the prevalence of milk allergy and food allergy in this population, which can increase the risk of transient pancreatitis. The treatment of food allergy induced pancreatitis can be controlled by a strict diet with allergen elimination, in pair with profuse hydration. Corticosteroids may also be used [6].

\section{Conclusion}

In conclusion, milk allergy should be considered as a possible cause of transient acute pancreatitis in patients with no other known cause with a prior history of this disorder.

\section{References}

1. Uc A, Husain S (2019) Pancreatitis in children. Gastroenterology 156(7): 1969-1978.

2. https://www.healio.com/pediatrics/journals/pedann/2017-5-465/\%7B4d2c661d-794d-4b0e-a7f2-f4f4e86991a1\%7D/an-update-onpediatric-pancreatitis

3. Restrepo R, Hagerott H, Kulkarni S, Yasrebi M (2016) Acute pancreatitis in pediatric patients: Demographics, etiology and diagnostic imaging. Journal of Roentgenology 206(3): 632-644.

4. Siegel MJ, Martin KW, Worthington JL (1987) Normal and abnormal pancreas in children: US studies. Radiology 165(1): 15-18.

5. Inada Y, Nakamura T, Zaitsu M (2020) Acute transient pancreatitis associated with milk allergy in an infant. Clinical Case Letters 57 (8): 756.

6. Manohar M, Verma AK, Venkateshaiah SU, Goyal H, Mishra A (2018) Food induced acute pancreatitis. Dig Dis Sci 62(12): 3287-3297. 